\title{
When distance apart: The roles of emotional-social intelligence on trust among individuals engaging in long distance relationships
}

Ridhoi Meilona Purba*

Margaret Khoman

University of Sumatera Utara

\begin{abstract}
We examined the role of emotional-social intelligence on trust, among couples engaging in long-termed long-distance romantic relationship (6 to 84 months), with meeting intensity between 1-12 times within a year. The results of this correlational study demonstrated that in general, individuals' emotional intelligence predicted greater trust toward partner. However, the main component of emotional intelligence that predicted trust was not intrapersonal or interpersonal skills, but other emotional-social skills (stress management, adaptation, mood). Discussion was focused on the importance of each component of emotional-social intelligence on trust, among couples engaging in long-termed long-distance relationship.
\end{abstract}

Keywords: Emotional-social intelligence, trust, long-distance romantic relationships

* Correspondence concerning this article should be addressed to Ridhoi Meilona Purba through e-mail: meilona faye@yahoo.com 
"... Wherever you go. Whatever you do. I will be right here waiting for you. Whatever
it takes. Or how my heart breaks. I will be right here waiting for you..."

(Richard Marx - I'll be right here waiting for you)

Long-distance geographical separation is a barrier for lovers or couples to develop healthy romantic relationships (Sahlstein, 2004), because it reduces the frequency and quality of communication and physical meeting (Rindfuss \& Stephen, 1990; Stafford \& Reske, 1990). It would also give rise to the feeling of detachment, uncertainty, and hesitation among couples, especially regarding the longevity of their romantic relationship (Lydon, Pierce, \&O'Reagan, 1997; Pistole, Roberts, \& Chapman, 2010; van Horn, et al., 2005). As the implication, the probability for long-distance relationships to fail is greater than it is to succeed (Beebe, Beebe, \& Redmond, 2004; van Horn, et al., 2005). Although research on long-distance relationships tends to show pessimistic trends, just as described by the lyrics of Richard Marx's song cited above, some individuals or couples would persist to maintain their romantic relationships, while distance apart. In the present study, we are interested on some factors that help couples to endure their romantic relationships, while distance apart. Specifically, we examined the role of emotional-social intelligence on individuals trust toward their partner while engaging in long-distance relationships.

\section{Trust and long-distance romantic relationships}

Failure in maintaining long-distance romantic relationships may be caused by reduced disclosure and assuredness of relationships longevity (van Horn, et al., 2005; Lydon, Pierce, \& O'Reagan, 1997). This disclosure and assuredness is related with the extent of which individuals trust their partner (Planalp \& Honeycutt, 1985). Trust can be defined as the expectation that a partner can be relied upon to be responsive to one's needs, both now and in the future (Rempel, Holmes, Zanna, 1985; Holmes \& Rempel, 1989). Trust is developed when individuals perceives their partner as engaging in actions promoting or maintaining their romantic relationships (Wieselquist, Rusbult, Foster, \& Agnew, 1999). Trust is also a representation of individuals' commitment toward their partner (Rusbult, Verette, Whitney, Slovik, \& Lipkus, 1991; van Lange et al., 1997). People with strong trust feels more satisfied with their relationship, are more willing to forego or drive away tempting alternative partners, and invest more in their relationship in both material and nonmaterial ways (Wieselquist et al., 1999). Thus, people who trust their partner strongly are those who would be able to forego and maintain their romantic relationship when their partner is distance apart (Anderson \& Emmers-Sommer, 2006).

\section{Emotional-social intelligence, long-distance romantic relationships, and trust}

Long-distance romantic relationships is a life challenge, in which most individuals feels attachment and disclosure toward partner as well as their assuredness of relationships longevity is challenged (van Horn, et al., 2005). Emotional-social intelligence constitutes individuals intrapersonal (e.g., self-awareness: knowing own feeling), interpersonal (e.g., empathy: knowing other people's feeling) and other social-emotional skills (e.g., stress management, adaptation, mood) that would help facilitate them to successfully overcome life challenges (see Bar-On, 1997, 2000, 2001, 2006). In other words, individuals with high emotional-social intelligence are those who are capable in expressing themselves to their partner understand and relate with their partner, as well as overcoming challenges of engaging in long-distance relationships. 


\section{Intrapersonal skills and trust}

According to Bar-On's $(1997,2006)$ model of emotional-social intelligence, intrapersonal skills is basically the extent of which individuals are able to value themselves (i.e., selfregard), acknowledge and manage their own emotions (i.e., self-awareness), assertive, independent, and actualizing themselves. These set of skills about one's own self is important in developing trust toward partner. For example, previous research has shown that the extent of which individuals are able to understand and regulate their own emotions is associated with higher relationships quality (Brackett, Warner, \& Bosco, 2005). This may be due to the importance of one's own emotion in determining their trust towards others (i.e., partner; Tschannen-Moran, \& Hoy, 2000), in which positive emotions (e.g., happiness) promotes trust, while negative emotions (e.g., anger) depreciates it (Dunn, \& Schweitzer, 2005). Thus, these sets of skills about one's own self (i.e., intrapersonal skills) is an important factor in determining trust among couples who engage in long-distance relationships.

\section{Interpersonal skills and trust}

Interpersonal skill is basically individuals' ability in understanding others, which constitute the ability to empathize, being socially responsible, and to establish interpersonal relationships with others (Bar-On, 1997, 2001, 2006). These set of skills is also important for individuals engaging in long-distance romantic relationships. For example, empathy, which is individuals' ability to recognize, understand, and attend other people's feeling (Bar-On, 2001 ) is associated with healthy romantic relationships (Davies \& Oathout, 1987). This may be due to the positive association of empathy with trust, in which high understanding towards partner's feelings is essential in trust development (Feng, Lazar, \& Preece, 2003). As the implication, the ability to understand and relating with others (i.e., interpersonal skills) may help individuals engaging in long-distance romantic relationships to maintain trust towards partner.

\section{Other emotional-social skills and trust}

Bar-On's model of emotional-social intelligence $(1997,2006)$ also incorporates other set of skills (stress management, adaptation, and mood) that may facilitate individuals in overcoming challenges in life. This set of skills is also important for couples engaging in long-distance romantic relationships. For example, previous study shows that relationships quality among Vietnam veterans who were diagnosed with stress disorder (post-traumatic stress disorder) tended to have lesser intimate relationships quality compared veterans with no such disorder (Riggs, Byrne, Weather, \& Litz, 1998). In addition, stress is also associated with abusive actions toward partner (Avonne \& Virginia, 1987). However, trust toward those who provide social support is an important factor that would help individuals to overcome stress (Grace \& Thomasschill, 1986). As suggested by Bar-On's (2006) model of emotionalsocial intelligence, the ability to identify and make use of resources that would help reduce stress is part of stress management skill. Thus, individuals who possessed high degree of stress management skill would make use trust as means of managing daily life stress. This would include trusting their partner.

\section{The present study and hypotheses}

In the present study, we examined the role of emotional-social intelligence on trust toward partner, among individuals engaging in long-distance relationships. We hypothesized that high emotional-social intelligence individuals would possessed high degree of trust toward partner (Hypothesis 1). Specifically, individuals degree of intrapersonal (Hypothesis 1a), interpersonal (Hypothesis 1b), and other social-emotional skills (Hypothesis 1c) would all uniquely associated with trust. 


\section{METHOD}

\section{Participants}

Participants were 120 people (50 male, 70 female). Eighty four (70\%) of participants were 17 to 22 years old, 31 (26\%) participants were 23 to 28 years old, and the remaining (4\%) were over 29 years old. Most participants (74 people or $62 \%$ ) have been engaging longdistance relationships between 1 to 3 years, 24 people (20\%) for 3 to 5 years, just 6 people $(5 \%)$ between 5 to 7 years, and the remaining (16 people or 14\%) for less than a year.

\section{Measurements and procedures}

After agreeing to participate voluntarily, the participants filled a questionnaire measuring emotional-social intelligence and trust toward partner. We developed both scales in the form of a 5 points Likert scale $(1=$ not at all $-5=$ very much $)$. Upon completion, participants were thanked and debriefed.

Our emotional-social intelligence scale was build basing on Bar-On's (1997, 2006) emotional-social intelligence model. This scale consists of 25 items composing three subscales (intrapersonal, interpersonal, and other emotional-social skills). The intrapersonal skill scale consist of 10 items (e.g., "I am able to recognize the situation of which I feel anxious", "I always make use of my abilities to make my life more meaningful"; $\alpha=.72$ ). The interpersonal skill scale consist of 5 items (e.g., "I would ask for forgiveness when I recognize my friend's anger for certain transgression that I committed", "I am capable of starting a conversation with others easily"; $\alpha=.44$ ). The measures of stress management, adaptation, and general mood was merged to form other emotional-social skills scale, because of their high intercorrelation (e.g., "I always know how to solve my problems", "I can easily adapted to new environment"; 10 items; $\alpha=.79$ ). The trust scale was build basing on Johnson and Johnson (1997) consisting of 10 items (e.g., "I would provide my partner with the materials needed to help him/her solving problems", I do not hesitate to make my point of view to my partner" $\alpha=.89$ ).

\section{RESULTS}

\section{Descriptive}

To analyze our data, scales were created by averaging items. General information about participants' score on each measurement is presented in Table 1. Participants on average scored very closely to the mid-point of all scales. The correlation between measures is presented in Table 3. In general, intrapersonal, interpersonal, and other emotional-social skill, were all correlated with trust.

Tabel 1. Descriptive statistics

\begin{tabular}{lccc}
\hline & $M$ & $S D$ & Skewness \\
\hline Intrapersonal skills & 2.94 & 0.34 & -0.49 \\
Interpersonal skills & 2.90 & 0.35 & 0.32 \\
Other emotional-social skills & 2.91 & 0.34 & -0.19 \\
Trust & 3.16 & 0.32 & 0.22 \\
\hline
\end{tabular}

\section{Emotional-social intelligence and trust}

We hypothesized that emotional-social intelligence in general would predict trust among couples engaging in long distance relationships (Hypothesis 1), we also hypothesized that each sub-skills of emotional intelligence (intrapersonal, interpersonal, other emotional-social 
skills) would uniquely associated with trust (Hypothesis 1a, 1b, 1c). To test these hypotheses, we regressed simultaneously Intrapersonal, Interpersonal, and Other Emotional-Social skills as predictor of Trust. The results yielded a significant equation, $F(3,116)=10.94, R^{2}=.22$, $p=.001$. As expected, in support of Hypothesis 1, emotional-social intelligence in general affected trust among individuals who engage in long-termed long-distance romantic relationships. However, as can be seen in Table 3, the contribution of intrapersonal and interpersonal skill on trust were only marginal, providing little support for Hypothesis 1a and 1b. Finally, in support for Hypothesis 1c, other emotional-social skill was a unique predictor of trust (again see Table 3).

Tabel 2. Intrapersonal, interpersonal, and other social-emotional skills contribution in predicting trust

\begin{tabular}{lccc}
\hline & $\beta$ & $t$ & $p$ \\
\hline Intrapersonal skills & 0.50 & 1.39 & .17 \\
Interpersonal skills & 0.14 & 1.62 & .11 \\
Other emotional-social skills & 0.28 & 2.63 & .01 \\
\hline
\end{tabular}

Tabel 3. Correlation between measures

\begin{tabular}{lccc}
\hline & Interpersonal skills & $\begin{array}{c}\text { Other emotional-social skills } \\
\text { (stress management, } \\
\text { adaptability, mood) }\end{array}$ & Trust \\
\hline Intrapersonal skills & $.35^{*}$ & $.64^{*}$ & $.38^{*}$ \\
Interpersonal skills & $.34^{*}$ & $.29^{*}$ \\
Emotional-social skills & & $.43^{*}$ \\
\hline
\end{tabular}

${ }^{*} p<.01$

\section{DISCUSSIONS}

In the present research we examine the relationship of emotional-social intelligence on trust towards partner among people who engaged in long termed-long distance relationships (LDR). We demonstrated that emotional intelligence in general predicted the level of trust towards one's partner among people who engaged in long distance relationships. This research suggests that people who managed to cope with the challenges imposed from engaging in long distance relationships are those who are capable in managing their emotions adequately. However, looking in more specificity, inter and intrapersonal skill was not the main component of emotional intelligence that predicted trust. Instead, level of trust was mainly predicted by the other emotional social intelligence (stress management, adaptation, and mood). Discussion regarding the results is as followed.

One reason to engage in intimate relationships is to attain social support, because social support is considered as one of the key factor in reducing stress and enhancing people's health and well-being (e.g., Turner, 1981; La Greca \& Harrison, 2005). As suggested by previous research, one of the key components of social support is positive interaction (Sherbourne \& Stewart, 1991). Long-distance relationships couples are lacking of mutual interaction. As the consequence, individuals engaging in long-distance relationships might relyies less social support from their partner and seek others (e.g., friends) for social support. Thus individuals committed to long distance relationships might developed a different mechanism of coping with daily life stress. Because of this circumstance, individuals' interpersonal skill towards their partner becomes less important for their romantic relationships. 
Previously, some research has reported that engaging in long distance relationships itself is stressful. For example, people who engage in long distance relationships felt moral burden regarding their relationships, this moral burden is often associated with stress and relationships dissatisfaction (Lydon, Pierce, and O'Regan, 1997). Therefore, having the skills to manage stress and to adapt with the circumstance of geographical separation is required in order to maintain the romantic relationships. As this research demonstrated, people with high other emotional social skills (stress management, adaptation, and mood regulation) are indeed those who could trust their partner.

Some limitation needs to be mentioned. First, our measure of interpersonal skills was not as reliable as we expected. Therefore, replication using more reliable scales is needed. Second, our approach was purely passive, replication using more sophisticated approach, such as the Experience Sampling Method (Csikzentmihalyi, 1997) might be able to tap more accurately how emotional-social intelligence affect trust among couples engaging in longdistance relationships.

Finally, we would like to give a suggestion for further research. The present research demonstrated that people who are able maintain long-distance relationships are those who are high in other emotional-social intelligence (stress management, adaptation, and mood). As previous research have suggested, people are often enggaged in romantic relationships because it is one means of attaining social support. Since inter and intrapersonal skills becomes less relevant for partner engaging in long-distance relationships, it is possible that people who succeded in long-distance relationship might have developed an alternative means of getting social support. This alternative might come from friends and family. As suggested by a research, people, especially women, tended to seek social support from family and friends after the death of a spouse (Kaunonen, Tarkka, Paunonen, \& Laippala, 1999). This suggested the possibility that people who are high in other social-emotional intelligence (stress management, adaptation, and mood) are people who are able to seek alternative source for social support as subtitute of their partner. We highly recommend future research to address this question.

\section{REFERENCE}

Anderson, T. L., \& Emmers-Sommer, T. M. (2006). Predictors of relationship satisfaction in online romantic relationships. Communication Studies, 57, 153-172.

Avonne, M., \& Virginia, B. (1987). Power affiliation motivation, stress, and abuse in intimate relationships. Journal of Personality and Social Psychology, 52, 203-210.

Bar-On, R. (1997). The Emotional Quotient Inventory (EQ-i): Technical manual. Toronto: Multi-Health System.

Bar-On, R. (2000). Emotional and social intelligence: Insights from the Emotional Quotient Inventory. In R. Bar-On, \& J. D. Parker (Eds.), The Handbook of Emotional Intelligence: Theory, Development, Assessment, and Application at Home, School, and in the Workplace (p. 528). CA: Jossey-Bass.

Bar-On, R. (2001). Emotional intelligence and self-actualization. In J. Ciarrochi, J. Forgas, \& J. D. Mayer (Eds.), Emotional intelligence in everyday life: A scientific inquiry. New York: Psychology Press.

Bar-On, R. (2006). The Bar-On model of emotional intelligence (ESI). Psychothema, 18, 1325.

Beebe, S. A., Beebe, S. J., \& Redmond, M. V. (2004). Interpersonal communication: Relating to others (4 ed.). Boston: Pearson Education. 
Brackett, M. A., Warner, R. M., \& Bosco, J. S. (2005). Emotional intelligence and relationship quality among couples. Personal Relationships, 12, 197-212. doi: 10.1111/j.1350-4126.2005.00111.x

Csikszentmihalyi, M. (1997). Finding Flow: The psychology of engagement with everyday life. Harper Collins.

Davies, M. H., \& Oathout, H. A. (1987). Maintenance of satisfaction in romantic relationships: Empathy and relational competence. Journal of Personality and Social Psychology, 53, 397-410.

Dunn, J. R., \& Schweitzer, M. E. (2005). Feeling and believing: The influence of emotion on trust. Journal of Personality and Social Psychology, 88, 736-748. doi: 10.1037/00223514.88.5.736

Feng, J., Lazar, J., \& Preece, J. (2004). Empathy and online interpersonal trust: A fragile relationship. Behavior and Information Technology, 23, 97-106. doi: 10.1080/01449290310001659240

Grace, G. D., \& Thomasschill. (1986). Social support and coping style differences in subjects high and low in interpersonal trust. Psychological Reports, 59, 584-586. doi: 10.2466/pr0.1986.59.2.584

Holmes, J. G., \& Rempel, J. K. (1989). Trust in close relationships. Review of Personality and Social Psychology, 10, 187-220.

Johnson, D., \& Johnson, F. (1997). Join together, group theory, and group skills (6 ed.). Boston: Allyn \& Bacon.

Kaukonen, M., Tarkka, M., Paunonen, M., \& Laippala, P. (1999). Grief and social support after the death of a spouse. Journal of Advance Nursing, 30, 1304-1311. doi: 10.1046/j.1365-2648.1999.01220.x

Lydon, J., Pierce, T., \& O'Regan, S. (1997). Coping with moral commitment to long-distance dating relationship. Journal of Personality and Social Psychology, 73, 104-113.

Pistole, M. C., Roberts, A., \& Chapman, M. L. (2010). Attachment, relationship maintenance, and stress in long distance and geographically close romantic relationships. Journal of Social and Personal Relationships, 27, 535-552. doi: 10.1177/0265407510363427

Planalp, S., \& Honeycutt, J. M. (1985). Events that increase uncertainty in personal relationships. Human Communication Research, 11, 593-604.

Rempel, J. K., Holmes, J. G., \& Zanna, M. P. (1985). Trust in close relationships. Journal of Personality and Social Psychology, 49, 95-112.

Riggs, D. S., Byrne, C. A., Weather, F. W., \& Litz, B. T. (1998). The quality of the intimate relationships of male Vietnam veterans: Problems associated with posttraumatic stress disorder. Journal of Traumatic Stress, 11, 87-101. doi: 10.1023/A:1024409200155

Rindfuss, R. R., \& Stephen, E. H. (1990). Marital noncohabitation: Separation does not make the heart grow fonder. Journal of Marriage and the Family, 52, 259-270.

Rusbult, C. E., Whitney, G. A., Slovik, L. F., \& Lipkus, I. (1991). Accomodation processes in close relationships: Theory and preliminary empirical evidence. Journal of Personality and Social Psychology, 60, 53-78.

Sahlstein. (2004). Relating at distance: Negotiating being together and being apart in longdistance relationships. Journal of Social and Personal Relationships, 21, 689-710. doi: 10.1177/0265407504046115 
Sherbourne, C. D., \& Stewart, A. L. (1991). The MOS social support survey. Social science and Medicine, 32, 705-714.

Stafford, L., \& Reske, J. R. (1990). Idealization and communication in long-distance premarital relationships. Family Relations, 39, 274-279.

Tschannen-Moran, M., \& Hoy, W. K. (2000). A multidisciplinary analysis of the nature, meaning, and measurement of trust. Review of Educational Research, 70, 547-593. doi: $10.3102 / 00346543070004547$

van Horn, K. R., Arnone, A., Nesbitt, K., Desllets, L., Sears, T., Griffin, M., \& Brudi, R. (2005). Physical distance and interpersonal characteristics in college students' romantic relationships. Personal Relationships, 4, 25-34. doi: 10.1037/0022-3514.53.2.397

van Lange, P. A., Rusbult, C. E., Drigotas, S. M., Arriaga, X. B., Witcher, B. S., \& Cox, C. L. (1997). Willingness to sacrifice in close relationships. Journal of Personality and Social Psychology, 72, 1373-1395.

Wieselquist, J., Rusbult, C. E., Foster, C. A., \& Agnew, C. R. (1999). Commitment, prorelationship behavior, and trust in close relationships. Journal of Personality and Social Psychology, 77, 942-956. 